\title{
Dinámica de la cobertura urbana de la ciudad de San Ramón, Alajuela, 1991-2018
}

\author{
Dynamics of the urban coverage of the San Ramón city, Alajuela, 1991-2018 \\ Enzo Barrientos Ávila ${ }^{1}$ \\ Ismael Guido Granados ${ }^{2}$ \\ Michael Moya Calderón³.
}

Fecha de recepción: 19-09-2019

Fecha de aceptación: 21-05-2020

\begin{abstract}
Resumen
América Latina se ha convertido en una de las regiones más urbanizadas del planeta, lo cual se refleja en todos los niveles de la jerarquía del sistema urbano, desde las áreas metropolitanas de los diferentes países, aglomeraciones urbanas, ciudades intermedias, secundarias y terciarias. Dado lo anterior, surge el interés por determinar la dinámica de la cobertura urbana en el casco central y la periferia del distrito de San Ramón, Alajuela, Costa Rica, en el período comprendido entre 1991 y 2018. Mediante el procesamiento de información geoespacial, propiamente imágenes satelitales Landsat 5, ASTER y Sentinel 2a de los años 1991, 2001, 2011 y 2018, se lograron determinar las hectáreas de cobertura urbana y de suelo urbano. Mediante el cálculo de la Tasa de Cambio Anual (TCA) se especificaron las ganancias y pérdidas de cada cobertura en el período analizado y la Tasa de Crecimiento Urbano (TCU) permitió identificar el crecimiento de la mancha urbana entre períodos. Los resultados revelan que entre el año 1991 y 2001 se dio el mayor aumento de la cobertura urbana en 54,80\%, entre 2001 y 2011 el desarrollo fue de un 21,68\% y entre 2011 y 2018 de un 49,43\%. La Tasa de Crecimiento Anual muestra que en todos los períodos hay ganancia de cobertura urbana y pérdida de suelo urbano, siendo el período 2011-2018 donde se presenta la mayor tasa de ganancia (5,15\%). El estudio permite concluir que el proceso de urbanización tiende a aumentar, según el período estudiado, lo cual concuerda con la dinámica de otras ciudades del país.
\end{abstract}

Palabras claves: cobertura urbana, suelo urbano, ciudades, teledetección, San Ramón, sensores remotos.

1 Bachiller en Gestión de Recursos Naturales, Universidad de Costa Rica, Sede Occidente, Costa Rica. Fundación Bosque Nuboso de Occidente (FUBONO). Correo electrónico: enzob2093@gmail.com

2 Magíster en Desarrollo Sostenible- Conservación Biológica, Docente e Investigador en Universidad de Costa Rica, Sede Occidente, Costa Rica. Programa de Investigaciones en Gestión Sostenible de los Recursos Naturales (PIRENA). Correo electrónico: ismael.guido@ucr.ac.cr

3 Magíster en Desarrollo Sostenible-Conservación Biológica, Docente e Investigador en Universidad de Costa Rica, Sede Occidente, Costa Rica. Programa de Investigaciones en Gestión Sostenible de los Recursos Naturales (PIRENA). Correo electrónico: michael.moya_c@ucr.ac.cr 


\begin{abstract}
Latin America has become one of the most urbanized regions on the planet, which is reflected at all levels of the hierarchy of the urban system, from the metropolitan areas of the different countries, urban agglomerations, intermediate, secondary, and tertiary cities. Given this, the interest arises to determine the dynamics of urban coverage in the San Ramón district - Alajuela, Costa Rica, and its peripheral area, in the period between 1991 and 2018. Through the processing of geospatial information, properly Landsat 5, ASTER, and Sentinel 2a satellite images of the years 1991, 2001, 2011, and 2018, it was possible to determine the areas (in hectares) of urban coverage and urban land. By calculating the Annual Change Rate (TCA), the gains and losses of each coverage in the analyzed period were determined and the Urban Growth Rate (TCU) allowed to identify the growth of the urban area between periods of time. The results show that between 1991 and 2001 there was the largest increase in urban coverage (54, 80\%), between 2001 and 2011 the increase was 21, 68\%, and between 2011 and 2018, 49,43\%. The Annual Growth Rate shows that in all periods there is a gain in urban coverage and loss of urban land, with the period 2011-2018 showing the highest rate of gain in urban coverage $(5,15 \%)$. The study concludes that the urbanization process has tended to increase in the period of time studied, which is consistent with the dynamics of other cities in the country.
\end{abstract}

Key words: urban cover, urban ground, cities, teledetection, remote sensing, San Ramón

\section{Introducción}

América Latina es una de las regiones más urbanizadas del mundo (Angotti, 2013), casi el 80\% de su población vive actualmente en ciudades, una escala superior incluso a la del grupo de países más desarrollados (ONU-Hábitat, 2012). El aumento de sus habitantes y la migración del campo a la ciudad genera mayor demanda de espacios para albergar a los nuevos residentes, lo cual detona una secuencia de urbanización de crecimiento rápido e incontrolado, que ha puesto en alto riesgo al medio ambiente, a la ecología y a los recursos terrestres de manera crítica. Dentro de los espacios de urbanización se incluyen todos los terrenos desarrollados, también las infraestructuras de comercio, residencia, industria y de otro tipo (Hassan y Southworth, 2018).

Esta dinámica transformadora hacia la artificialización de coberturas naturales aumenta con mayor velocidad en las ciudades, con un patrón que parte del centro hacia las periferias, la cual obedece a la lógica del mercado según intereses privados y económicos (Soto, 2015). De igual forma, la carencia de áreas urbanas con posible uso horizontal en el centro de las ciudades obliga al aprovechamiento de los espacios hacia el borde.

Estas situaciones no son ajenas a la realidad de Costa Rica. En el caso de la Gran Área Metropolitana, se tiene un espacio urbanizado o construido de aproximadamente 34818 hectáreas, donde la mancha urbana crece a una tasa cada vez menor con respecto a otros períodos, lo cual se explica por el agotamiento del área disponible para urbanización (Sánchez, 2019). En el caso de la ciudad de San Ramón, la cual se originó a partir de una aldea erigida oficialmente en 1844 en el marco de la colonización del territorio nacional (Pineda y Castro, 1986), esta realidad se ha presentado desde la década de los ochentas. Lo anterior lleva a que la vida en la ciudad cambie y se pierda ese aspecto rural de los campos sembrados de café o caña entre áreas pobladas con características urbanas (Castro y Guido, 2001).

La carencia de un ordenamiento territorial planificado, que guíe el crecimiento urbanístico, generó una expansión desordenada de la ciudad, lo cual se abarca en el presente estudio con el objetivo de determinar la dinámica de la cobertura urbana en el casco central y la periferia del distrito de San Ramón en el período comprendido entre 1991 y 2018. Los resultados, obtenidos mediante el procesamiento de información geoespacial, conforman una línea base que permite el desarrollo de futuras investigaciones en el campo de estudio, las cuales ayuden a comprender de una mejor manera la dinámica de la variación de la cobertura urbana en ciudades secundarias y terciarias en constante crecimiento. 


\section{Materiales y métodos}

Área de estudio

La investigación se llevó a cabo en el cantón de San Ramón de Alajuela, Costa Rica. El área de estudio comprende una circunferencia de tres kilómetros de radio desde un centroide ubicado en el distrito principal del cantón (2827,31 hectáreas aproximadamente), que parte desde el sector más urbano hacia su periferia. El área abarca parte de los distritos de Alfaro, Santiago, San Rafael, San Isidro, San Juan, Concepción, Ángeles y Piedades Norte (Figura 1).

\section{Figura 1.}

Ubicación del área de estudio en el distrito Central de San Ramón y distritos cercanos .

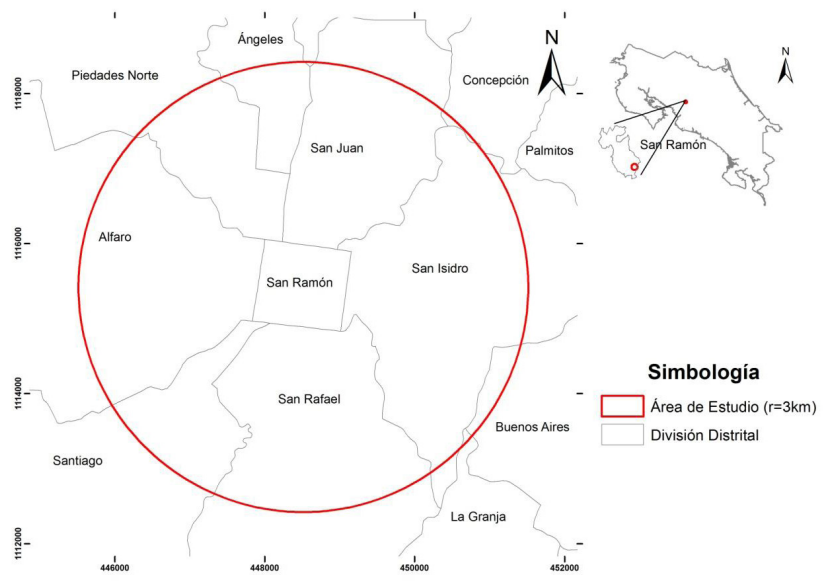

Fuente: elaborado por los autores.

\section{Metodología}

Para analizar la dinámica de la cobertura urbana se siguió un proceso dividido en tres etapas: 1) Determinar y clasificar la cobertura del suelo, 2) establecer la Tasa de Cambio Anual (TCA), y 3) especificar la Tasa de Crecimiento Urbano (TCU). A continuación, se detalla cada uno de estos estadios.

\subsection{Determinación y clasificación de cobertura del suelo}

Se consideraron los períodos: $\mathrm{t} 1=1991, \mathrm{t} 2=2001, \mathrm{t} 3=2001$, y t4=2018, debido a la disponibilidad de imágenes satelitales (Tabla 1). Se tomó como punto de partida la imagen más antigua que se logró adquirir (1991) y posteriormente una cada 10 años hasta llegar al año del estudio (2018). Se utilizó esta fuente de información debido a su disponibilidad y características, las cuales permiten realizar análisis en períodos extensos así como su facilidad para trabajar las clasificaciones de cobertura.

Tabla 1. Imágenes satelitales empleadas para realizar las clasificaciones de cobertura en los distintos años de análisis.

\begin{tabular}{|l|l|l|}
\hline Fecha & Satélite & Resolución espacial (m) \\
\hline 07/30/1991 & Landsat 5 & $\begin{array}{l}\text { VNIR SWIR 30 } \\
\text { TIR 120 }\end{array}$ \\
\hline 01/14/2001 & Landsat 5 & $\begin{array}{l}\text { VNIR SWIR 30 } \\
\text { TIR 120 }\end{array}$ \\
\hline 03/14/2011 & ASTER & $\begin{array}{l}\text { VNIR 15 } \\
\text { SWIR 30 } \\
\text { TIR 90 }\end{array}$ \\
\hline 04/01/2018 & Sentinel 2a & $10-60$ \\
\hline
\end{tabular}

Fuente: elaborado por los autores a partir de datos del Servicio Geológico de los Estados Unidos (USGS por sus siglas en inglés).

El proceso de clasificación de la cobertura se realizó mediante el software ENVI $5.3{ }^{\circledR}$ (Exelis Visual Information Solutions, 2015) el tipo de clasificación fue no-supervisada y se utilizó el sistema K-means para establecer cinco tipos de coberturas. Se empleó el método Quick Atmospheric Correction (QuAC) para realizar las correcciones atmosféricas en las imágenes satelitales.

Los resultados se procesaron en el software ArcGis 10.3 ( ) (ESRI, 2014) para corregir la clasificación y unificar las coberturas. Se establecieron dos categorías: suelo 
urbano y cobertura urbana, ya que el área de estudio es totalmente considerada una ciudad; sin embargo, hay zonas verdes, de cultivo y recreativas.

A continuación, se detallan las características de las dos coberturas utilizadas para este estudio (Tabla 2).

Tabla 2: Clasificación de coberturas en el área de estudio.

\begin{tabular}{|l|l|}
\hline Categoría & Descripción \\
\hline Cobertura urbana & $\begin{array}{l}\text { Todas las áreas que presentan un reemplazo } \\
\text { de la cobertura natural originaria por una } \\
\text { impermeable utilizada para actividades } \\
\text { humanas. Comprende las áreas residenciales, } \\
\text { comerciales, industriales y vías de } \\
\text { comunicación. }\end{array}$ \\
\hline Suelo urbano & $\begin{array}{l}\text { Todas las áreas que no presentan una } \\
\text { cobertura artificial, sin embargo, tampoco } \\
\text { presentan la originaria. Dentro de esta se } \\
\text { encuentran charrales, suelo descubierto, } \\
\text { zonas de cultivo, zonas de pastizal, zonas } \\
\text { verdes y recreativas. }\end{array}$ \\
\hline
\end{tabular}

Fuente: elaborado por los autores.

\subsection{Tasa de Cambio Anual (TCA)}

La TCA expresa el cambio (porcentual) de la superficie al inicio de cada año evaluado, lo cual determina las tasas de conversión entre coberturas, en este caso entre cobertura urbana y suelo urbano (Samaniego, 2013). Valores por debajo de cero indican que las categorías están perdiendo superficie y por el contrario, datos mayores a cero indican ganancias (Velázquez et al., 2002).

Para determinar la TCA se utilizó la metodología propuesta por la Organización de las Naciones Unidas para la Alimentación y la Agricultura FAO (por sus siglas en inglés) (1996), dada por la fórmula:

$$
T=\left[\frac{S_{2}}{S_{1}}\right]^{\frac{1}{n}}-1 * 100
$$

Donde, $\mathrm{T}$ es la tasa de cambio, $\mathrm{S}_{1}$ y $\mathrm{S}_{2}$ son las superficies de cobertura del suelo en el tiempo inicial y tiempo final respectivamente, la variable n corresponde al número de años entre las dos fechas. Para efectos de este estudio se determinaron cuatro tasas de cambio: 1) Período: 19912001, 2) 2001-2011, 3) 2011-2018 y 4)1991-2018.

\subsection{Tasa de Crecimiento Urbano (TCU)}

Por medio de la cobertura metropolitana, se analizó para los cuatro períodos la dinámica de crecimiento de la mancha urbana. Para este cálculo se empleó la metodología de Piña (2014) modificada en cuanto al nombre de la cobertura por utilizar, dada por la fórmula:

Donde, TCU es la tasa de crecimiento urbano, AU1 y AU2

$$
T C U=\frac{\left(A U_{2}-A U_{1}\right)}{A U_{1}} * 100
$$

son las áreas al inicio y al final del período de referencia.

\section{Resultados}

4.1 Determinación y clasificación de cobertura: los resultados de la clasificación final muestran una cobertura ciudad no predominante pero creciente desde el año 1991 al 2018 y un suelo urbano predominante, pero que va decreciendo desde el año 1991 al 2018 (Tabla 3).

Tabla 3: extensión de las coberturas en el área de estudio.

\begin{tabular}{|l|l|l|l|l|}
\hline Año & $\begin{array}{l}\text { Cobertura } \\
\text { urbana (ha) }\end{array}$ & $\begin{array}{l}\text { Porcentaje } \\
(\%)\end{array}$ & $\begin{array}{l}\text { Suelo urbano } \\
\text { (ha) }\end{array}$ & $\begin{array}{l}\text { Porcentaje } \\
(\%)\end{array}$ \\
\hline 1991 & 389,57 & 13,78 & 2437,73 & 86,22 \\
\hline 2001 & 603,05 & 21,33 & 2224,21 & 78,67 \\
\hline 2011 & 733,76 & 25,95 & 2093,40 & 74,05 \\
\hline 2018 & 1096,47 & 38,78 & 1730,84 & 61,22 \\
\hline
\end{tabular}

Fuente: elaborado por los autores.

Tal como se muestra en la Figura 2, desde 1991 (año base del estudio) ambos tipos de coberturas se acercan cada vez más a tener un mismo valor, lo cual demuestra una dinámica de avance de la cobertura urbana sobre la natural. 


\section{Figura 2.}

Dinámica de la cobertura urbana del casco central de la ciudad de San Ramón, Alajuela, 1991-2018.

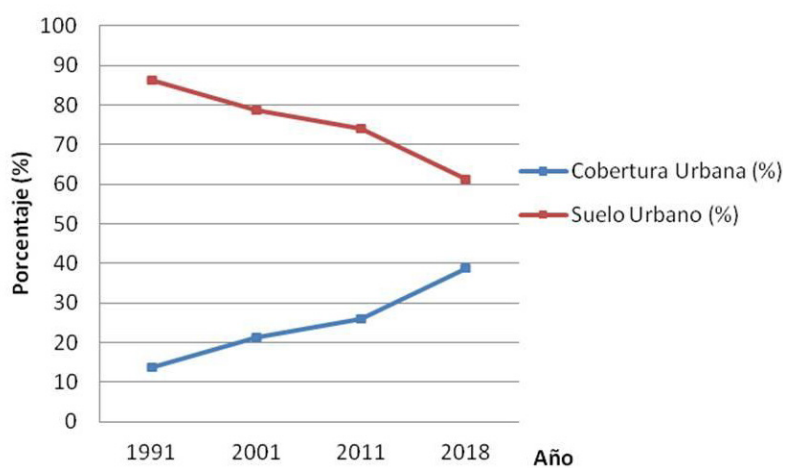

Fuente: elaborado por los autores.

\subsection{Tasa de Cambio Anual (TCA)}

Se presentan los resultados por cada uno de los períodos comparados.

\section{Período 1991-2001}

La TCA en este período muestra una ganancia de cobertura urbana $(\mathrm{TCA}>0)$ y una disminución $(\mathrm{TCA}<0)$ de este tipo de suelo (Figura 3). Dicho período revela la segunda tasa de aumento de cobertura de la urbe $(4,47 \%)$ (Figura 3 y Figura 6)

Figura 3.

Tasa de cambio anual período 1991-2001.
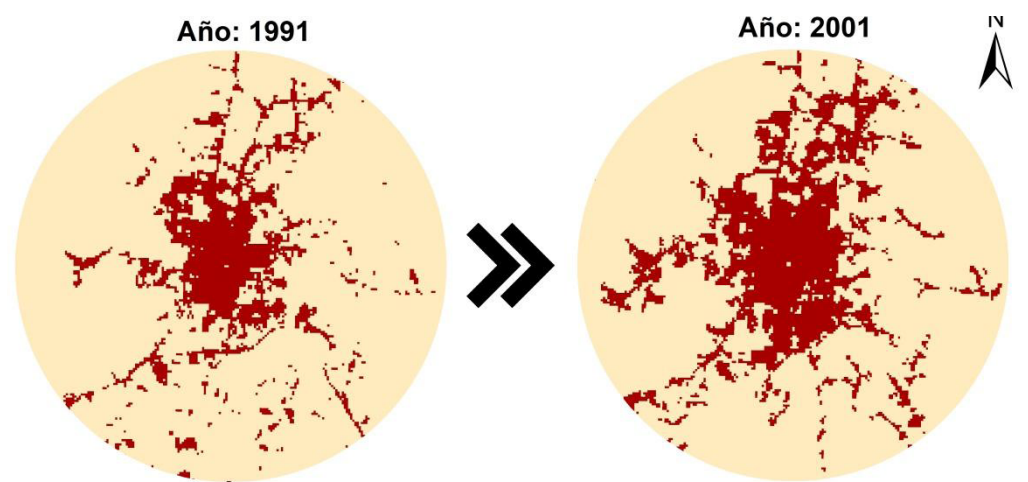

\begin{tabular}{|c|c|c|c|}
\hline \multicolumn{4}{|c|}{ Tasa de cambio anual período 1991-2001 } \\
\hline \multirow{2}{*}{ Categoría } & \multicolumn{2}{|c|}{ Hectáreas } & \multirow{2}{*}{ TCA (\%) } \\
\cline { 2 - 3 } Cobertura urbana & 3891 & 2001 & 4,47 \\
\hline Suelo urbano & 2437,73 & 603,05 & 2224,21 \\
\hline
\end{tabular}

SIMBOLOGÍA

Cobertura urbana

Suelo urbano

Fuente: elaborado por los autores.

\section{Período 2001-2011}

La TCA en este período muestra, al igual que el período anterior, una ganancia de cobertura urbana $(\mathrm{TCA}>0) \mathrm{y}$ una disminución $(\mathrm{TCA}<0)$ de este suelo. La ganancia es la más baja dentro de los años contemplados en el estudio
$(1,98 \%)$, así como la menor cifra de pérdida de suelo urbano (-o,6\%) (Figura 4 y Figura 6), siendo el período con menos cambios en cuanto a ganancias y pérdidas. 
Figura 4.

Tasa de cambio anual período 2001-2011.
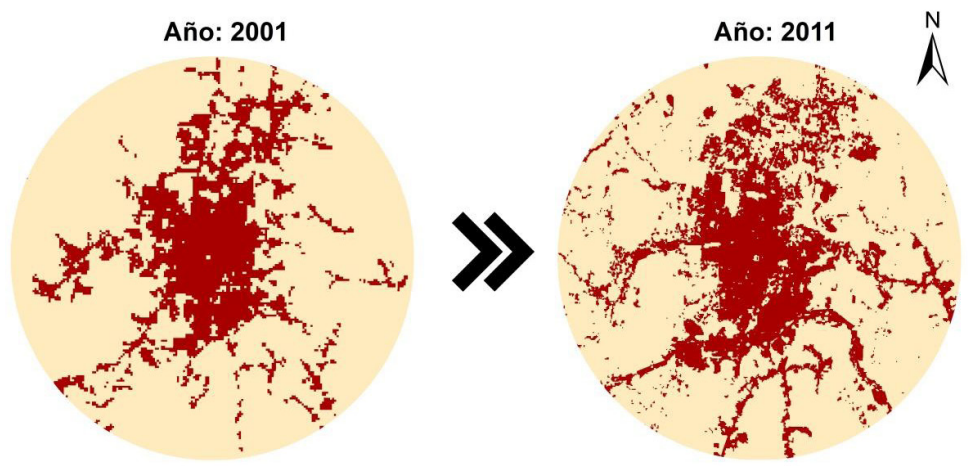

\begin{tabular}{|c|c|c|c|}
\hline \multicolumn{4}{|c|}{ Tasa de cambio anual periodo 1991-2001 } \\
\hline \multirow{2}{*}{ Categoría } & 1991 & 2001 & \multirow{2}{*}{ TCA (\%) } \\
\cline { 2 - 4 } Cobertura urbana & 389,57 & 603,05 & 4,47 \\
\hline Suelo urbano & 2437,73 & 2224,21 & $-0,91$ \\
\hline
\end{tabular}

SIMBOLOGÍA

Cobertura urbana

Suelo urbano

Fuente: elaborado por los autores.

\section{Período 2011-2018}

La TCA muestra la misma tendencia de los otros períodos analizados, con una disminución $(\mathrm{TCA}<\mathrm{O})$ del suelo incluso esta última presenta la mayor tasa de ganancia urbano y un aumento de dicha cobertura (TCA $>0$ ), donde desde 1991-2018 (5,15\%) (Figura 5).

Figura 5.

Tasa de cambio anual período 2011-2018.
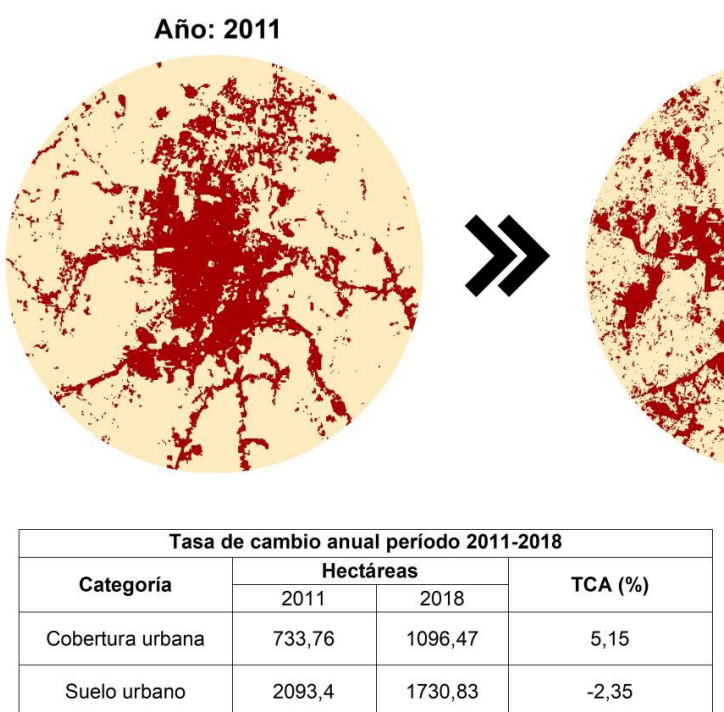

Año: 2018

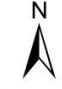

\begin{tabular}{|c|c|c|c|}
\hline \multirow{4}{*}{ Tasa de cambio anual período 2011-2018 } \\
\cline { 2 - 3 } Categoría & 2011 & Hectáreas & \multirow{2}{*}{ TCA (\%) } \\
\hline Cobertura urbana & 733,76 & 1096,47 & 5,15 \\
\hline Suelo urbano & 2093,4 & 1730,83 & $-2,35$ \\
\hline
\end{tabular}

SIMBOLOGÍA

Cobertura urbana

Suelo urbano

Fuente: elaborado por los autores. 


\section{Figura 6.}

Comparación de pérdidas y ganancias de cobertura urbana y suelo urbano.

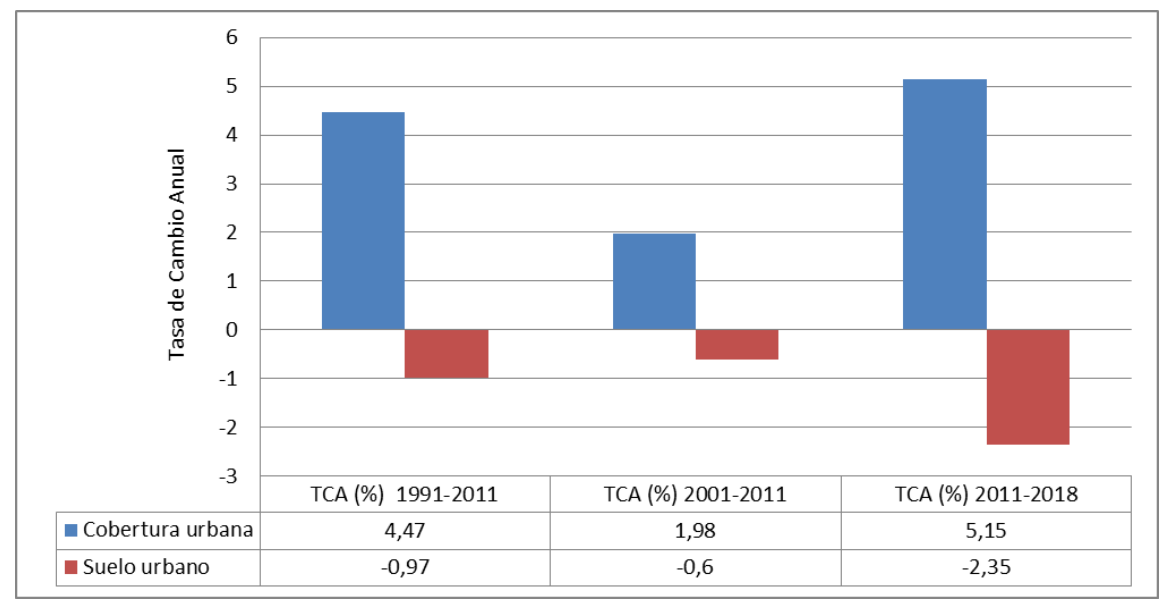

Fuente: elaborado por los autores.

\subsection{Tasa de Crecimiento Urbano (TCU)}

El área de estudio durante el año 1991 contaba con alrededor de 389,57 (ha) de cobertura urbana equivalente a un $13,78 \%$ del total de este suelo. Ya para el 2001 se da un aumento en la tasa de expansión de un 54,80\% comparada con el año 1991, es decir, se pasó de 389,57 ha a 603,05 (ha) de la cobertura de la ciudad (Tabla 3, Figura $7 \mathrm{a}$ y $7 \mathrm{~b})$.
En el año 2011 la tasa de crecimiento respecto al 2001 es de 21,68\% en donde aumenta en 130,71 (ha) el área de superficie con cobertura urbana. Por último, para el 2018 la cubierta de la urbe asciende a 1096, 47 (ha), con una tasa de crecimiento de 49,43\% respecto al año 2011(Tabla 4, Figura 7c).

Tabla 4: Tasa de crecimiento urbana del año 1991 al 2018.

\begin{tabular}{|l|l|l|l|}
\hline Año & Cobertura urbana (ha) & Tasa de crecimiento & Tasa de crecimiento promedio anual \\
\hline 1991 & 389,57 & - & - \\
\hline 2001 & 603,05 & 54,80 & 5,48 \\
\hline 2011 & 733,76 & 21,68 & 2,16 \\
\hline 2018 & 1096,47 & 49,43 & 6,17 \\
\hline
\end{tabular}

Fuente: elaborado por los autores. 


\section{Figura 7.}

Comparativa de la distribución de la cobertura urbana en lapsos de diez años en el área de estudio.

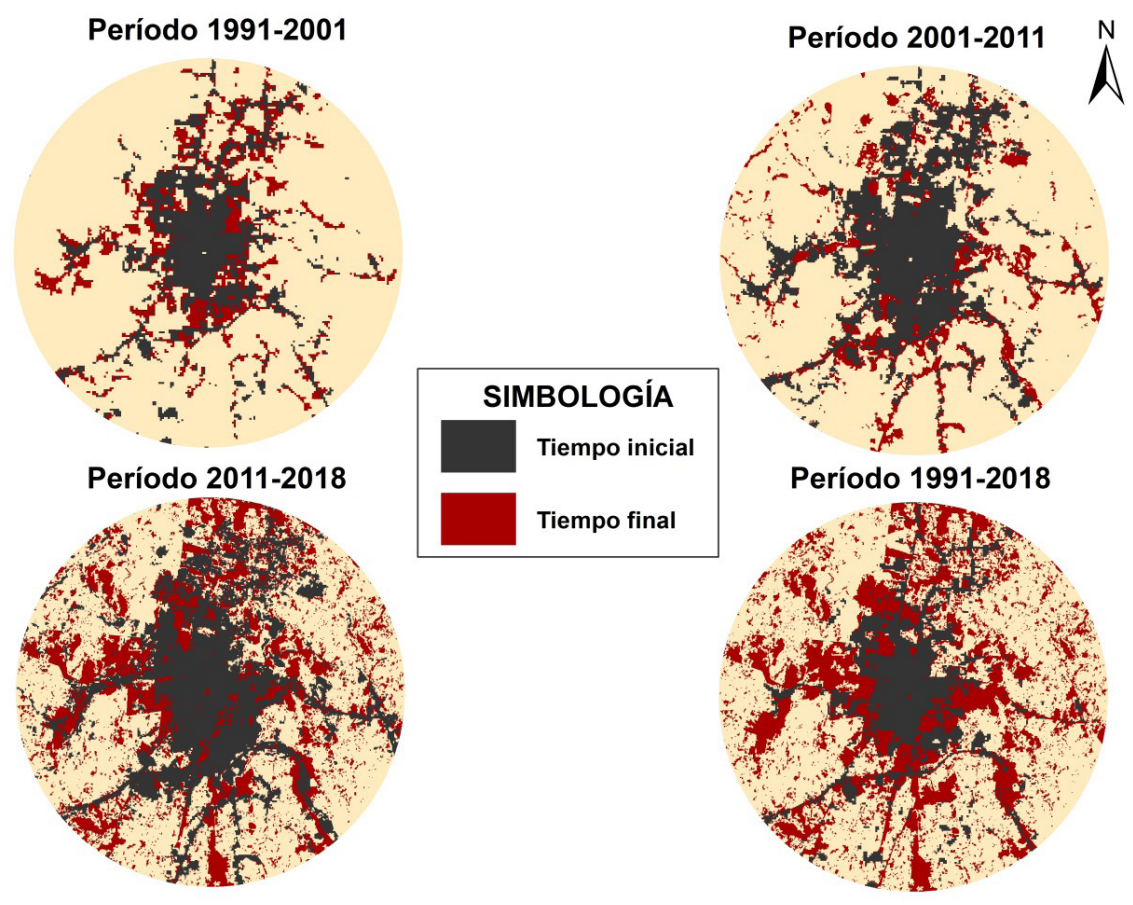

Fuente: elaborado por los autores.

Al realizar una comparación entre el año base del estudio (1991) y el año final (2018) con respecto a la tasa de crecimiento, se determina que es de un $181,45 \%$ (Figura 5d), y traducido a extensión territorial el aumento es de 706,90 (ha) lo cual representa 2,81 veces más de cobertura urbana.

\section{Discusión}

Una ciudad es más que una isla en medio de un territorio, posee un rol funcional porque conforma redes sociales y económicas con otras localidades, sin embargo, su desarrollo desde el enfoque del planeamiento de la ciudad se estima por medio de la expansión de la mancha urbana (Bazant, 2010). Es a partir de dicho enfoque que se condujo esta investigación, la cual tiene como objetivo conocer la dinámica espacial de la cobertura urbana. ProDUS-UCR (2017) estableció que el suelo denominado urbano se encontraba presente en todos los distritos del cantón de San Ramón, para un total de 1,2\% (12,7km²), siendo el distrito central el de mayor porcentaje (94,4\%). Sobre estos resultados es importante mencionar: 1) se obtuvieron por medio del procesamiento de una imagen satelital Landsat ETM+ del 2001, fotografías aéreas de 1998 y 1992, mapas de uso de suelo de 1989, así como una fotografía aérea del mosaico de ortofotos del 2008 y fotografías aéreas de los años 2005 y 2016 de Google Earth; 2) se utilizó una sola categoría para el uso urbano y 3 ) el área determinada correspondía al distrito Central. Los aspectos anteriores permiten explicar por qué hay diferencias con respecto a los resultados obtenidos por ProDUS-UCR y los de esta investigación.

A nivel metodológico, el presente estudio realizó un análisis basado exclusivamente en el procesamiento de imágenes satelitales. Además, se hizo uso de dos categorías para diferenciar entre cobertura y suelo urbano determinadas en un radio de tres kilómetros a partir del centro de la ciudad y no únicamente el distrito central. 
Dentro del análisis y procesamiento de información llevado a cabo, se determinó como uno de los principales hallazgos, que si bien el fenómeno de la expansión de la mancha urbana entre los períodos 1991-2018 no ha presentado cifras de expansión constante, en todos los períodos ha tendido a valores positivos (crecimiento). Sánchez (2019) determina esta misma tendencia al desarrollo para algunas ciudades intermedias de Costa Rica, por ejemplo, Pérez Zeledón expandió su mancha urbana en un 66\% entre 2003-2015, Guápiles un 66\% entre 2005-2015 y Ciudad Quesada un 51\% entre 20052016.

A pesar de que la tasa de crecimiento urbano de estas ciudades intermedias fue determinada para años diferentes a los del presente estudio, es posible comparar algunos datos para establecer el nivel de similitud. Entre 2001-2011 San Ramón presentó un 21,68\% de crecimiento, pero entre 2011-2018 hubo un aumento significativo de 49,43\%. Si se considera el período 2001-2018 esta tasa asciende a un $81,82 \%$, valor más alto que supera los determinados por Sánchez en su estudio.

Al comparar el crecimiento urbano para San Ramón en el período 2001-2011 con la Gran Área Metropolitana, se concluye que su expansión es similar. Según Sánchez (2019) para los años 1997-2010 el desarrollo fue de un 22,3\%, y por su parte Pujol y Pérez (2012), demuestran que el crecimiento interanual fue de $1,56 \%$ pasando de 27 044,9 ha en 1997 a 33 088,1 ha en 2010.

La tasa de cambio anual mostró su más alto dinamismo en el período 2011-2018 (Figura 6), donde se presentó la mayor ganancia de cobertura urbana. Si bien se podría considerar que estos resultados deben ser consistentes con el crecimiento de la tasa de cambio urbano, como se expuso anteriormente, esta tuvo su principal expansión entre 1991-2011 (Tabla 3). Las razones obedecen a la cantidad de años contemplada en el período 2011-2018 (8 años) diferente a la de 1991-2001 (10 años). Ambas muestran similitud en cuanto al período 2001-2011, el cual se caracteriza por presentar los valores más bajos (TCA=1,98 y TCU=21,68); se concluye que en este tiempo hubo una desaceleración en el proceso de expansión urbana. Futuras investigaciones sobre este tema podrían ayudar a comprender los factores socioeconómicos o políticos que expliquen la dinámica en estos años.

En el período 1991-2001 se presentó la segunda tasa de cambio anual más alta $(4,47)$ la cual es consistente, como se mencionó antes, con la mayor tasa de cambio urbano.

Anterior a la década de los noventas, varios autores ya habían venido estudiando la dinámica de la urbe del cantón de estudio. Castro y Guido (2001) apuntaban a que el proceso de urbanización en San Ramón se podía comprender a partir de aspectos como el cambio de las actividades económicas el cual inició desde la década de los 1980, donde el porcentaje de personas dedicadas a labores agrícolas y de extracción disminuyó. La población económicamente activa de ese entonces se dedicaba en mayor medida a labores de carácter cada vez más urbano, lo que conlleva a una mayor demanda y oferta de servicios. Además, estos autores muestran el crecimiento de la población en la ciudad, en el caso de San Ramón entre 1950-1973 incrementó un 146,73\%, y un 36\% entre 1973-1984.

El aumento de los habitantes genera a su vez mayor demanda de servicios que por lo general se concentran en la urbe (Castro y Guido, 2001), así como terrenos para la construcción de infraestructura destinada a casas y departamentos. Lo anterior se presentó en San Ramón entre 1990-200o con el auge de urbanizaciones como: Sesteo I y II, La Isla, Los Parques II y III, La Americana, Los Tucanes, Las Tres Marías II y más reciente, Los Lirios, Las Lomas, Otto Cooper y Vista de la Montaña.

Este aumento de la urbanización, como ya se mostró, se ha determinado a nivel de ciudades intermedias, Gran Área Metropolitana, pero también se manifiesta en la dinámica de la cobertura natural de Costa Rica, así lo expone el estudio de Sierra, Cambronero y Vega (2016) sobre los patrones y factores de cambio de la capa forestal de Costa Rica, 1987-2013. Los autores concluyen que el tipo de cobertura expandida con mayor rapidez fue la urbana e infraestructural (2,9\%/año). 
Las principales limitantes de este trabajo se asocian con la selección de los períodos de estudio, los cuales responden a la disponibilidad de datos geoespaciales y no a elementos socioeconómicos o políticos que aclaren los resultados de una manera precisa. Sin embargo, factores como recesión económica, incremento de urbanizaciones o infraestructura vial, pueden situarse dentro de cada período considerado y ofrecer elementos que ayuden a la explicación de los resultados.

Por otro lado, la metodología está condicionada a la disponibilidad de información geoespacial. No todas las imágenes provienen del mismo satélite debido a la presencia de nubes o la no disponibilidad de imágenes para ese año, por lo tanto, se requirieron datos geoespaciales de diferentes fuentes, lo cual implica una diferencia en la resolución del área que depende del satélite. Se recomienda para la metodología empleada, usar imágenes satelitales con la misma resolución espacial, utilizar diferentes resoluciones solo en caso de que no se obtenga de un año específico.

El estudio pretende ser una base para dar seguimiento al cambio de cobertura, por lo tanto, el seguir recolectando datos como puntos de comprobación es de vital importancia para obtener resultados más cercanos a la realidad; así mismo representa un insumo práctico para los análisis de los efectos del cambio climático relacionados con las variaciones de cobertura natural, desde un enfoque de secuelas de temperatura y la posibilidad de una isla de calor urbana, además de los efectos, la impermeabilización de los suelos en las inundaciones que frecuentan la zona.

En cuanto a recomendaciones, es importante destacar que los hallazgos del estudio permiten generar una línea base de información útil para el desarrollo de futuros trabajos, como por ejemplo las implicaciones del aumento de la mancha urbana en las temperaturas de la ciudad. En estudios sobre esta temática, se ha determinado por medio del uso de imágenes satelitales y la cobertura del suelo, que las mayores temperaturas se asocian con zonas urbanas y hacia las periferias se concentran los menores grados de calor (Barrientos y Moya, 2018). Esta alteración de temperaturas se asocia con el fenómeno de islas de calor urbano, las cuales varían con niveles máximos dentro de la ciudad, por lo general sin árboles, los cuales son un factor esencial en el calentamiento de la urbe (Municipalidad de Curridabat, 2019).

Otro de los estudios que se pueden potenciar, basados en los hallazgos, es el análisis cualitativo y cuantitativo de las causas de la expansión urbana en las últimas tres décadas. Estudios similares fueron conducidos por Casto y Guido (2001) para los años 1998 y 200o, pero consideran la información para el análisis de los años 1950, 1973 y 1984.

\section{Agradecimientos}

A la Vicerrectoría de Investigación, al Programa de Investigaciones en Gestión Sostenible de los Recursos Naturales (PIRENA) (540-B6-255) y la Coordinación de Investigación de la Sede de Occidente de la Universidad de Costa Rica por el apoyo brindado al proyecto: Diagnóstico y seguimiento del desarrollo socioambiental del cantón de San Ramón (540-B6-053).

\section{Bibliografía}

Angotti, T. (2013). Urban Latin America: Violence, Enclaves, and Struggles for Land. Latin American Perspectives 40(5), 5-20. https://doi. org/10.1177/oog4582X12466832

Barrientos, E., y Moya, M. (2018). El Efecto de la Cobertura del Suelo en la Variación de las Temperaturas Locales; Naranjo, Alajuela, Costa Rica, 2016. Revista Geográfica De América Central, 2(61), 205-219. https://doi.org/10.15359/rgac.61-2.7

Bazant, J. (2010). Expansión urbana incontrolada y paradigmas de la planeación urbana. Espacio abierto Cuaderno Venezolano de Sociología, 19 (3), 475-503. Recuperado el o1 de setiembre de 2020, de https://www.redalyc.org/articulo. oa?id=122/12215112003

Castro, S. y Guido, F. (2002). De pueblo a ciudad en los albores del siglo XXI el caso de San Ramón. Cuadernos de Antropología, 12, 123-134. 
Castro, S. y Guido, F. (2001). Urbanización fuera del área metropolitana en Costa Rica: aspectos generales y en estudio de caso. Pensamiento Actual, 2 (3), $54^{-65}$.

ESRI. (2014). ArcGIS Desktop: Release 10.3. Redlands, CA: Environmental System Research Institute.

Exelis Visual Information Solutions. (2015). ENVI 5.3. Boulder, Colorado: Exelis Visual Information Solutions.

González, R. (1994) El Régimen de tenencia de la tierra en Costa Rica. Heredia, EUNA.

Hassan, M. y Southworth, J. (2018). Analyzing Land Cover Change and Urban Growth Trajectories of the Mega-Urban Region of Dhaka Using Remotely Sensed Data and an Ensemble Classifier. Sustainability, 10 (10). https://doi.org/10.339o/ su10010010

Municipalidad de Curridabat. (2019). Islas de calor, impactos y respuestas: El caso del cantón de Curridabat. Curridabat, Costa Rica.

ONU-HABITAT. (2012). Estado de las ciudades de América Latina y el Caribe 2012 Rumbo a una nueva transición urbana. Recuperado el 04 de setiembre de 2020, de https://www.zaragoza.es/contenidos/ medioambiente/onu/newsletter12/887_spa.pdf

Organización de las Naciones Unidas para la agricultura y la Alimentación (FAO). (1996). Forest resources assessment 1990. Survey of tropical forest cover and study of change processes. Roma, Italia: FAO.

Pineda, M. y Castro S. (1986). Colonización, poblamiento y economía: San Ramón 1842-19oo. San José: Centro de Investigaciones Históricas, Universidad de Costa Rica.
Piña, G. (2014). Indicadores de desarrollo urbano sustentable para la Zona Metropolitana de Pachuca (Tesis de Maestría). El Colegio del Estado de Hidalgo, México.

ProDUS-UCR (Programa de Desarrollo Urbano SostenibleUniversidad de Costa Rica). (2017). Estrategia de promoción de inversiones en el cantón de San Ramón. Recuperado el 19 de agosto de 2019, de https://drive.google.com/file/d/oB55gdv LUtQ2aE91eXk1dGJEdoNPZXFOaG 5 sMUwwZ29CYUtr/view

Pujol, R. y Pérez, E (2012). Crecimiento urbano en la región metropolitana de San José, Costa Rica. Una exploración espacial y temporal de los determinantes del cambio de uso del suelo, 1986-2010. Recuperado el 19 de agosto de 2019, de https://www.lincolninst.edu/es/publications/ working-papers/crecimiento-urbano-en-laregion-metropolitana-san-jose-costa-rica.

Samaniego, N. 2013. Análisis de vulnerabilidad en zonas potenciales de recarga hídrica por efectos de cambios de uso de suelo y por variabilidad climática en la Microcuenca del Río Purires, Costa Rica. (Tesis Maestría). Centro Agronómico Tropical de Investigación y Enseñanza.

Sánchez, L. (2019). Patrones de crecimiento urbano y sus impactos sobre la movilidad. Informe Estado de la Nación en Desarrollo Humano Sostenible 2019. Recuperado el 27 de agosto de 2019, de http://repositorio.conare.ac.cr/ handle/20.500.12337/7817

Sierra, R; Cambronero, A; y Vega, E. (2016). Patrones y factores de cambio de la cobertura forestal natural de Costa Rica, 1987-2013. Recuperado el 29 de agosto de 2019, de http://reddcr.go.cr/ sites/default/files/centro-de-documentacion/ rsierraacambroneroevega_patrones_y_factores_ cus.pdf. 
Soto, J. (2015). El Crecimiento Urbano de las Ciudades: Enfoques Desarrollista, Autoritario, Neoliberal y Sustentable. Paradigma Económico, 7, 127-149.

Velázquez, A; Mas, J; Díaz, J; Mayorga, R; Alcántara, P; Castro, R; Fernández, T; Bocco, G; Ezcurra, E; y Palacios, J. (2002). Patrones y tasas de cambio de usos de suelo en México. Gaceta Ecológica, 62, 21-37. Recuperado el 19 de agosto de 2019, de http://redalyc.uaemex.mx/pdf/539/53906202.pdf 